\title{
MODELO SEMIÓTICO DE LEITURA DE INSCRIÇÕES: APLICAÇÃO NA EDUCAÇÃO EM QUÍMICA
}

\author{
Mikeas Silva de Lima ${ }^{a}$ e Salete Linhares Queiroz ${ }^{\text {a,*,i) }}$ \\ anstituto de Química de São Carlos, Universidade de São Paulo, 13560-970 São Carlos - SP, Brasil
}

Recebido em 17/02/2020; aceito em 30/04/2020; publicado na web em 18/06/2020

\begin{abstract}
SEMIOTIC MODEL FOR READING INSCRIPTIONS: APPLICATION IN CHEMISTRY EDUCATION. Inscriptions - graphs, diagrams, photographs, tables, and so forth - are central to scientific practice. In this study, a semiotic model was used to evaluate the reading of inscriptions by undergraduate chemistry students when giving oral presentations based on original research articles about environmental chemistry. Results revealed that the model helps to identify the extension of the adequacy of using inscriptions by the students in communicative situations. Potentialities and limitations of the model for chemistry education are discussed.
\end{abstract}

Keywords: inscriptions; higher education; chemistry.

\section{INTRODUÇÃO}

O uso dos modos de comunicação gráfico-visuais na sala de aula e nos livros didáticos de ciências é notavelmente frequente. No esforço de transformar dados científicos em fatos para que outros pesquisadores se convençam da importância do que fazem e da verdade que dizem, os cientistas precisam desenvolver habilidades de persuasão e de construção de representações desses fatos, ${ }^{1}$ como gráficos, fotografias, mapas, diagramas, esquemas, tabelas, equações etc. Logo, a comunicação científica exige o conhecimento de como trabalhar com os modos visuais de comunicação e com diversas formas de representações. O termo inscrição surge na obra de Latour e Woolgar, ${ }^{1}$ e nomeia representações visuais materiais, inerentemente elaboradas em laboratórios de pesquisa para retratar os objetos e fenômenos de estudo da ciência, tais como as citadas anteriormente.

A seleção de um tipo de inscrição para representação de um fenômeno e inserção em determinado texto científico se relaciona com os tipos de informações (visuais, numéricas, conceituais etc.) a serem representados. ${ }^{2}$ Os diferentes tipos de inscrições se estendem ao longo de um continuum, entre inscrições próximas ao mundo dos fenômenos e objetos (MFO) e inscrições próximas ao mundo dos conceitos e teorias (MCT). ${ }^{2}$ A Figura 1 apresenta um continuum com diferentes tipos de inscrições associados à espectroscopia de absorção atômica.

Quanto mais próxima da extremidade do MFO a inscrição estiver, como fotografias, mapas e desenhos icônicos (ou desenhos naturalísticos, aqui entendidos como representações visuais que possuem determinada semelhança com o que representam e colocam em evidência detalhes do mesmo), menor é o nível de abstração e maior a quantidade de informação contextualizada e detalhes que ela pode apresentar, além da maior semelhança com o que está sendo representado. Os esforços de leitura requeridos estão relacionados à identificação das semelhanças icônicas entre a inscrição e os objetos e fenômenos representados. ${ }^{2} \mathrm{Na}$ direção do MCT, as inscrições, como gráficos, tabelas e equações, não possuem, ou possuem pouca semelhança com os fenômenos que elas representam, ou seja, o nível de abstração e informações contidas na inscrição aumenta. Ao se desprenderem de um contexto específico, as inscrições podem estar ligadas a diversos contextos, ou seja, elas ganham poder de generalização. Uma fotografia de um rio representa um rio específico, mas o desenho icônico de um rio pode representar diversos rios.

Apesar de as inscrições serem ferramentas culturais criadas e utilizadas nas ciências naturais, seu uso não se restringe apenas à pesquisa científica. ${ }^{3}$ Essas estão intimamente relacionadas com a comunicação científica. De fato, a produção de um artigo, por exemplo, gira em torno da adaptação das inscrições utilizadas na pesquisa científica, ${ }^{3,4}$ na qual o papel da inscrição é evidenciar conclusões, assim como servir de matéria-prima na elaboração de justificativas, modelos e argumentos, que darão a confiabilidade necessária ao conhecimento produzido.

Dada a importância das inscrições para a ciência e sua forte presença em textos didáticos e salas de aulas, o fato de diversos estudantes do ensino médio e superior apresentarem dificuldades no seu uso e interpretação é inquietante. ${ }^{2}$ Com relação ao contexto nacional, Lima e Queiroz ${ }^{5}$ analisaram menções a práticas de inscrições na seção Relatos de Sala de Aula da revista Química Nova na Escola e verificaram que a recorrência do seu uso em ambientes de ensino de química ainda é escassa.

Dentre as diversas práticas do ensino de química que colocam os estudantes em contato com as inscrições de uma maneira autêntica

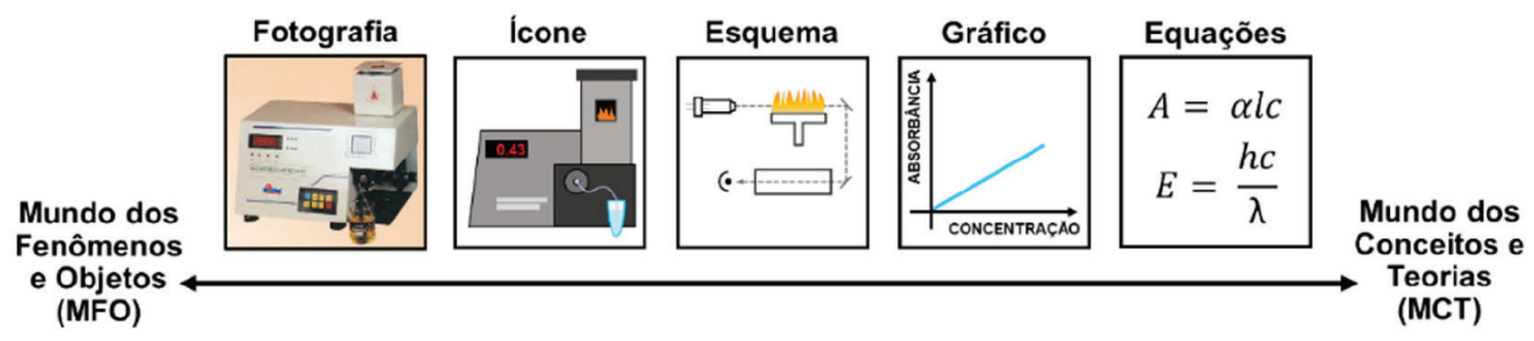

Figura 1. Continuum com diversos tipos de inscrições relacionadas à espectroscopia de absorção atômica

*e-mail: salete@iqsc.usp.br 
e favorável ao desenvolvimento de habilidade comunicativas está a produção de gêneros orais, tais como seminários, exposições orais (EO), debates etc. ${ }^{6}$ No entanto, a oralidade nem sempre é tomada como objeto de ensino, com uma reflexão de suas especificidades e trabalhada a partir de objetivos e necessidades de aprendizagem dessa modalidade. São poucas também as pesquisas que se voltam para uma sistematização do ensino da mesma. Cabe esclarecer que na perspectiva do presente trabalho o termo oralidade não está associado a campos de pesquisa específicos, tratando-se simplesmente da capacidade de expressão oral dos indivíduos.

Roth et $a l^{2}{ }^{2}$ apresentam evidências de que os estudantes desenvolvem um entendimento acerca das inscrições de forma crítica quando as utilizam com finalidades retóricas, a fim de convencer seus pares sobre os resultados de suas investigações. Tais finalidades são evidenciadas, por exemplo, durante a produção de EO, que exigem dos estudantes a vivência de momentos de argumentação sobre as soluções encontradas para problemas investigados. Ou seja, além de uma leitura e interpretação satisfatória de inscrições, a realização de EO dessa natureza também tem potencial para promover a criticidade frente às mesmas.

Com base em investigação de como a falta de familiaridade e como as regras de convenções afetam a leitura e interpretação das inscrições, Roth e Bowen ${ }^{4}$ propõem um Modelo Semiótico de Leitura de Inscrições (MSLI), ainda pouco conhecido no Brasil. O objetivo geral desse trabalho é ilustrar a utilização do MSLI para avaliar o uso e a leitura de inscrições no ensino de química durante a produção do gênero EO. Essas foram elaboradas por graduandos em química, enquanto matriculados em disciplina de comunicação científica, a partir da leitura de artigos originais de pesquisa, doravante apenas artigos, publicados nesta Revista. A partir disso, configuram-se como objetivos específicos a tessitura de comentários sobre as potencialidades e limitações do MSLI para proporcionar um melhor entendimento e avaliação da produção de gêneros orais e a contribuição para a expansão dos aportes teórico-metodológicos que podem ajudar na reavaliação das atividades de ensino-aprendizagem que visam o desenvolvimento de habilidades relacionadas à interpretação e uso de inscrições. Como a EO é difundida em diversas áreas e disciplinas, os resultados advindos deste trabalho encontram aplicações em outros contextos.

\section{MODELO SEMIÓTICO DE LEITURA DE INSCRIÇÕES}

O ponto de partida de elaboração do Modelo se encontra na concepção triádica apresentada abaixo. A Figura 2 ilustra os elementos que compõem a relação triádica de signo, que são o sinal, o referente e o interpretante. Os sentidos emergem a partir das relações entre esses elementos.

\section{Sinal}

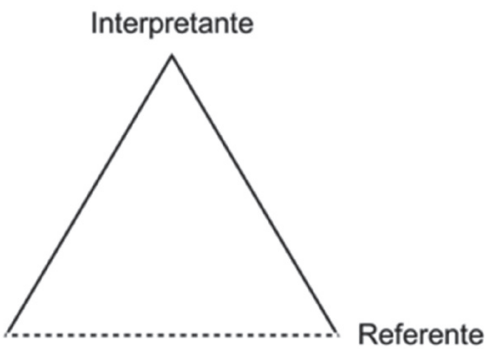

Figura 2. Concepção triádica de signo de Roth e Bowen ${ }^{4}$

Na base do triângulo se encontram o sinal e o referente. O sinal é uma entidade que se refere ou representa outra e o referente pode ser um conceito, fenômeno, entidade física ou abstrata, ações, classificações, direções ou relações etc. Em Roth e Bowen, ${ }^{4}$ referindo-se às inscrições, os sinais tratados são os traços materiais, como letras, palavras, fotos e gráficos. Não há uma relação direta entre o sinal e o referente, como pode ser observado na base do triângulo, por meio da linha tracejada. Tal relação é indireta e mediada pelo interpretante no topo do triângulo, que é definido como as teorias, definições ou interpretações feitas sobre o sinal e sua relação com o referente. A produção de interpretante, ou seja, de extração de sentidos da inscrição é um processo chamado semiose. Assim, os interpretantes, além de traduzirem o sinal em um referente, articulam e apresentam a nossa compreensão sobre ele. ${ }^{7}$

Existe uma diferença entre sinal e signo. Segundo Azevedo Netto, o sinal é "qualquer forma gráfica, sonora, geológica, astronômica etc. de assinalação (...) destituída de mecanismos para a construção de significados" (p. 2). À medida que ocorre a criação de significados, cria-se o signo, ou seja, algo convencionado, composto pelo sinal, o referente e o interpretante.

A fim de exemplificarmos tais elementos, apresentamos a Figura 3, que traz um gráfico da variação da concentração de reagentes e produtos de acordo com o tempo de uma reação genérica, reagente $\rightleftharpoons$ produto, até o equilíbrio químico. Nessa inscrição, palavras como "reagentes", "produtos", entre outras, assim como os traços e curvas são sinais (constituídos como traços de tinta no papel) que significam, para um químico por exemplo, objetos e fenômenos (referentes) com os quais ele tem experiência diariamente. Dentre as diversas possíveis reações em situação de equilíbrio com as quais a inscrição da Figura 3 está associada, uma delas é $\mathrm{N}_{2} \mathrm{O}_{4} \rightleftharpoons 2 \mathrm{NO}_{2}$. Já a asserção "a concentração de reagentes diminui com o passar do tempo" é um possível interpretante que um químico pode gerar a partir da visualização da Figura 3.

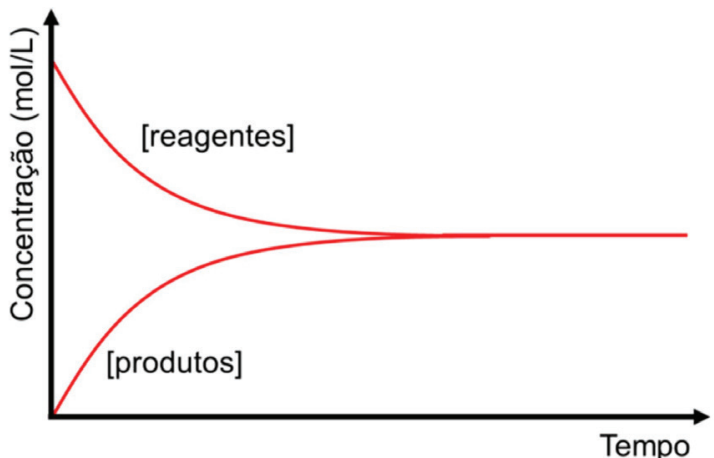

Figura 3. Gráfico de concentração vs tempo para uma reação genérica

Roth e Bowen ${ }^{4}$ justificam as relações encontradas a partir do MSLI $^{8-12}$ com base na assertiva de que, por natureza, as coisas não têm significados, mas estes são construídos em relação a um determinado contexto e comunidade e, dessa forma, de acordo com a situação, pessoa ou época, os significados podem variar. A partir disso, se isolados, os sinais não podem ser completamente compreendidos ou estudados. Entende-se, portanto, que os sinais utilizados na composição de uma mensagem são complementares entre si. Assim, os propósitos pretendidos em condições específicas de comunicação e o contexto é que determinam o uso de certas formas de representação ao invés de outras.

De fato, diversos sinais próprios da química não farão sentido fora da comunidade científica. Por exemplo, considerando-se a fórmula molecular $\mathrm{CH}_{3} \mathrm{Cl}$, na visão dos inexperientes no estudo da química e nas práticas da comunidade química, $\mathrm{CH}_{3} \mathrm{Cl}$ é simplesmente uma sequência de letras com um número no meio, sem algum sentido. Aspectos como maiúsculo, minúsculo, subscrito supostamente serão reconhecidos, mas toda a mensagem que o símbolo carrega não será decodificada. Já para os membros da comunidade química ou para 
os que têm experiência com a linguagem dela, os quais partilham do modo como essa representação deve ser lida, os aspectos mencionados são identificados e relacionados a um modo de comunicação bastante específico, a representação de moléculas. Tais recursos levam à interpretação de que $\mathrm{CH}_{3} \mathrm{Cl}$ representa a molécula do clorometano, na qual um átomo de carbono está ligado a três átomos de hidrogênio e um de cloro.

Com base nessas considerações, Roth e Bowen ${ }^{4}$ propõem um Modelo que vem esclarecer como se dá o processo de leitura de inscrições. O Modelo, ilustrado na Figura 4, é constituído de duas partes, ou processos de leitura de uma inscrição. Esses e seus elementos componentes serão elucidados a seguir.

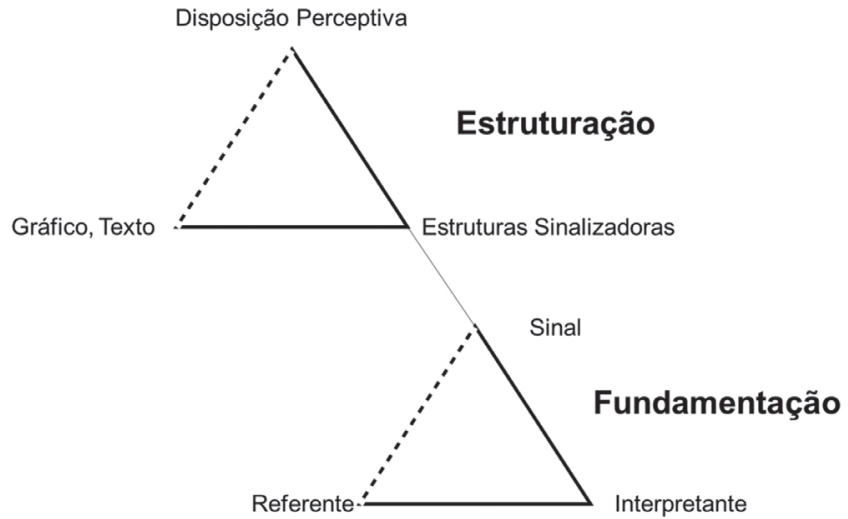

Figura 4. MSLI de Roth e Bowen

O primeiro processo de leitura de uma inscrição é denominado estruturação, e corresponde ao triângulo superior da Figura 4. Nesse processo, o leitor, por meio de uma análise perceptiva, identifica elementos significativos na inscrição, ou seja, é o momento que o leitor estrutura a inscrição em torno de elementos significativos buscando avaliar se tais servem ou não para a produção de sentidos. Nessa etapa, a atividade de leitura ainda é interna à inscrição, sem tentar relacioná-la com algum referente, ou seja, somente os elementos que a constituem e sua estrutura interna são trabalhados.

A presença da estruturação e dos seus elementos no Modelo evidencia a importância da análise do início primordial da atividade de leitura de inscrições e as condições necessárias para sua realização. ${ }^{2}$ A estruturação de uma inscrição contém os seguintes elementos: gráfico, (elementos visuais e texto verbal) que representa a forma material (impressa, computadorizada etc.) da inscrição e dos sinais que a compõem; disposição perceptiva, que representa características e experiências que os leitores trazem consigo, que afetam e guiam esse processo; e estruturas sinalizadoras, que são ordens e tendências, porém sem conexão ainda com os fenômenos que a inscrição pretende representar.

Com base no gráfico da Figura 3, exemplificamos como ocorre o processo de estruturação: o leitor, pode, a partir da sua disposição perceptiva para com os elementos gráficos da inscrição, identificar como estruturas sinalizadoras o máximo de concentração, o mínimo de concentração, a interseção entre as curvas de concentração dos reagentes e produtos etc. A partir disso, alguns interpretantes já podem ser elaborados, como "concentração dos reagentes igual a dos produtos". Os tipos de estruturas sinalizadoras identificados variam de indivíduo a indivíduo, de acordo com a sua disposição perceptiva, a qual é uma característica pessoal e moldada pelas suas experiências com práticas de inscrições.

Uma vez que a inscrição está estruturada em torno de elementos significativos, estes podem ser considerados como um sinal, algo que se refere a algum fenômeno externo a ele mesmo. O processo de conectar um sinal ao seu referente, por meio da elaboração de interpretantes, é chamado de processo de fundamentação (triângulo inferior da Figura 4). Os elementos desse processo, e como ele ocorre, foram definidos e exemplificados anteriormente, a partir das Figuras 2 e 3, de forma que o processo de fundamentação é o momento em que o leitor faz elaborações verbais (interpretantes) para a realização de uma leitura relevante da inscrição. ${ }^{4}$

É importante ressaltar ainda que, segundo Roth e Bowen, ${ }^{4} \mathrm{o}$ processo de fundamentação é inerentemente dialético. Isso significa que a obtenção de uma relação entre sinal e referente é resultado de movimentos mútuos, de construção sintética de possíveis referentes a partir dos sinais e de redução analítica de situações e fenômenos em sinais. Esses movimentos auxiliam ainda para reafirmar ao leitor da inscrição que as estruturas sinalizadoras salientadas por ele servem como sinais para a fundamentação, e assim desdobrar os significados e realizar a compreensão da inscrição.

Neste trabalho, por meio da observação da presença dos elementos do MSLI nas relações elucidadas enquanto o indivíduo elabora uma representação visual material ou descreve os referentes dessa representação, pretende-se discutir os processos de leitura e interpretação de inscrições durante a realização do gênero EO produzidos com base em artigos por graduandos em química, buscando apontar contribuições do MSLI para avaliação da mencionada produção.

\section{CONTEXTO DE APLICAÇÃO DA PROPOSTA E ANÁLISE DOS DADOS}

Com base nos objetivos descritos anteriormente, tomamos para avaliação, com base no MSLI, uma EO produzida por estudantes do primeiro ano do curso de Bacharelado em Química do Instituto de Química de São Carlos, da Universidade de São Paulo, enquanto matriculados na disciplina Comunicação e Expressão em Linguagem Científica II (CELCII), que tem por objetivo o desenvolvimento de habilidades comunicativas orais.

No início do semestre, a turma foi dividida em grupos, e cada grupo recebeu um artigo, retirado desta Revista, para realização das seguintes atividades, com base no conteúdo do artigo: produção de uma EO prévia inicial pautada nas seções Introdução e Procedimento Experimental do artigo, produção de um pôster acadêmico, e de uma EO final abordando todo o conteúdo do artigo.

A EO final, escolhida para ser avaliada neste trabalho, foi elaborada com base no artigo intitulado "Avaliação do teor de metais em sedimento do rio Betari no Parque Estadual Turístico do Alto Ribeira - PETAR, São Paulo, Brasil" de Cotta et al. ${ }^{13}$ O PETAR é uma unidade de conservação da Mata Atlântica, localizada no sul do estado de São Paulo. Desde um século atrás, as atividades no PETAR, assim como no Vale do Ribeira, têm afetado essa região, colocando-a em constante risco ecológico. A mineradora de Furnas fazia a extração, principalmente, de galena, pirita e esfalerita, produzindo 7000 a 8000 toneladas de chumbo, no período de 1919 a 1968. E, durante todo esse período, o material de rejeito era despejado no rio Furnas. Um dos objetivos do trabalho era avaliar a capacidade de troca catiônica (CTC) dos metais chumbo, cádmio, cobre, zinco, alumínio, crômio, ferro, manganês e zinco ao longo dos rios Furnas e Betari. Também foi avaliada a biodisponibilidade dos mesmos metais totais e pseudototais acumulados em sedimentos do rio. Os resultados encontrados foram concentrações pseudototais de cobre, zinco e chumbo, assim como, zinco e chumbo biodisponíveis, acima do valor máximo permitido.

Para a avaliação, inicialmente, foi realizada uma caracterização da EO, identificando a quantidade e os tipos de inscrições utilizados, visando detectar padrões e tendências que poderiam ou não estar conectadas com o processo de produção de sentidos. Foi realizada em seguida a avaliação da transcrição da fala do aluno expositor da EO, 
que consiste em debulhar o mesmo a fim de encontrar os processos e elementos do MSLI.

Com base no trabalho de Roth e Bowen ${ }^{4}$ e Keller, ${ }^{14}$ adotamos os critérios apresentados no Quadro 1 para a identificação de cada elemento do MSLI. Os resultados encontrados fornecem o entendimento de como se deu o processo de produção de sentidos e o encandeamento de geração de sinais, referentes e interpretantes a partir das inscrições apresentadas na EO.

Quadro 1. Critérios utilizados para identificação dos elementos do MSLI na transcrição da EO

\begin{tabular}{|c|c|}
\hline Elemento & Critério de Identificação \\
\hline Disposição Perceptiva & $\begin{array}{l}\text { Menção a elementos que buscam direcion } \\
\text { atenção da audiência aos aspectos das inscric } \\
\text { e as relações entre os mesmos. }\end{array}$ \\
\hline Gráfico & Menção ao que está materializado nos $s l$ \\
\hline Estrutura Sinalizadora & $\begin{array}{l}\text { Menção a elementos, ordens e tendên } \\
\text { presentes na inscrição sem conexão com } \\
\text { fenômenos que a inscrição pretende represer }\end{array}$ \\
\hline Sinal & $\begin{array}{l}\text { Menção a elementos, ordens e tendên } \\
\text { presentes na inscrição em conexão com os } \\
\text { nômenos que a inscrição pretende represer } \\
\text { através da elaboração de interpretantes. }\end{array}$ \\
\hline Referente & $\begin{array}{l}\text { Menção a situações externas aos sinais da } \\
\text { crição e externas à inscrição em si. }\end{array}$ \\
\hline Interpretante & $\begin{array}{l}\text { Afirmação ou conclusão elaboradas sobre a } \\
\text { crição, os sinais e suas relações com o refere }\end{array}$ \\
\hline \multicolumn{2}{|c|}{$\begin{array}{l}\text { No processo de identificação dos elementos do MSLI, cada } \\
\text { ento em que um novo slide é introduzido se constitui uma Uni } \\
\text { Avaliação (UA), numerada de acordo com o número do me } \\
\text { ssa forma, a UA- } 5 \text { se refere ao quinto slide utilizando na EO, s } \\
\text { mposta pelo que foi projetado durante a apresentação e a transc } \\
\text { fala do aluno. Nem todas as UA que apresentam inscrições s } \\
\text { cutidas, as que não forem constam como Material Suplemen }\end{array}$} \\
\hline
\end{tabular}

A respeito das características da EO produzida, essa continha 15 slides, os quais foram apresentados em 15 min por apenas um dos integrantes do grupo, em uma sequência esperada de Introdução, Procedimento Experimental, Resultados e Conclusões. Todos os slides possuíam alguma inscrição, sendo utilizadas, no total, 16 inscrições. No entanto, nem todas as inscrições foram lidas pelo aluno expositor, de forma que algumas inscrições apareciam apenas de maneira decorativa ou ilustrativa.

É possível estabelecer uma relação entre os tipos de inscrições presentes no artigo de Cotta et al. ${ }^{13}$ e os tipos de inscrições presentes na EO. No artigo, são encontrados tabelas, gráficos, equação e mapa, ou seja, inscrições, em sua maioria, próximas ao MCT. Os tipos de inscrições presentes na EO não se limitam aos tipos presentes no artigo, e se distribuem por todo o continuum (Figura 1), devido à presença de fotografias, ícones e esquemas (inscrições próximas do MFO).

As inscrições utilizadas na EO se distribuíram entre três temáticas principais: quatro inscrições relacionadas ao Contexto da Pesquisa (CP), sete inscrições relacionadas com os Procedimentos Experimentais (PE) e cinco inscrições relacionadas aos Resultados (R). As inscrições com a temática $\mathrm{CP}$ são aquelas inseridas na primeira parte da EO e têm a função principal de apresentar à audiência o contexto local da pesquisa, o PETAR e a problemática em estudo.
Nessa temática estão presentes três fotografias e um desenho icônico. As inscrições com a temática PE aparecem no meio da apresentação e têm como função demonstrar o procedimento experimental, desde os pontos de coleta até os aparelhos utilizados para quantificação dos metais. Nessa temática estão presentes um mapa, dois esquemas, uma fotografia, um ícone, um fluxograma e uma equação. As inscrições que pertencem à temática $\mathrm{R}$ são três tabelas, um gráfico e uma fotografia.

Nota-se que no início da apresentação predominam inscrições próximas ao MFO, e à medida que a apresentação se encaminha para o final ocorre a predominância de inscrições próximas ao MCT. Isso ocorre devido às características do gênero EO. Segundo Pozzer e Roth,${ }^{15}$ dentro da ciência há preferência pela utilização de inscrições do lado direito do continuum (Figura 1), ou seja, inscrições próximas ao MCT. Já nos textos didáticos, usam-se predominantemente fotografias e desenhos icônicos. A EO, no contexto da sala de aula e da comunicação científica, se configura como um gênero que carrega perspectivas do discurso didático e do científico. Portanto, é notável, durante o início da apresentação, quando o estudante está realizando uma introdução, o uso de inscrições tais como fotografias e desenhos icônicos, ou seja, inscrições próximas ao MFO, já que seu discurso apresenta características mais didáticas. Quando o estudante se direciona para exposição dos procedimentos e resultados, o seu discurso ganha caráter predominantemente científico, e as inscrições recorrentes nessa etapa são tabelas, equações e gráficos, inscrições mais generalizadas, próximas do MCT. Dessa forma, a EO pode proporcionar para o aluno expositor e para a audiência a expansão do contato com inscrições de diferentes naturezas, o que fomenta o desenvolvimento das habilidades comunicativas com inscrições e a capacidade de articular várias formas de representação.

\section{Presença de Elementos do MSLI}

Como relatado anteriormente, nem todas as inscrições foram lidas efetivamente pelo aluno expositor. Um total de $50 \%$ das inscrições aparecia apenas de maneira decorativa (18\%) ou ilustrativa (32\%). As inscrições decorativas foram assim classificadas devido ao aluno expositor não as citar em sua fala. Já com relação às inscrições ilustrativas, ele meramente nomeava o que era possível nelas visualizar, sem ressaltar nenhum detalhe ou conectá-las com o seu discurso posterior ou anterior. Dessa forma, devido à ausência de um discurso que nos permitisse buscar e identificar elementos do MSLI, a leitura e produção de sentidos dessas inscrições não foram avaliadas.

As inscrições que sofreram um processo de leitura que permitia análise da produção de sentidos com o MSLI, são aqui denominadas de inscrições complementares, que são aquelas que deram suporte e estavam altamente associadas à fala do aluno expositor, sendo elaboradas, descritas, explicadas e classificadas pelo mesmo, proporcionando à audiência diversos recursos semióticos para a elaboração de sentidos. De maneira reflexiva, entende-se que a fala elabora a inscrição e a inscrição também elabora a fala do estudante. Ou seja, existe uma relação de motivação, tanto do texto verbal oral para com a inscrição, quanto da inscrição para com o texto verbal. Na EO aqui avaliada, as inscrições complementares se constituem de um esquema, um mapa, um gráfico, três tabelas e uma equação, presentes nas temáticas PE e R. A seguir, aspectos da leitura e da produção de sentidos dessas inscrições serão elucidadas à luz do MSLI.

\section{MSLI em Mapa}

O Quadro 2 apresenta a transcrição e a identificação dos processos do MSLI na leitura do único mapa presente na EO. Os trechos seguidos de (PE) são aqueles em que predominam o processo de estruturação e os trechos seguidos de (PF) são aqueles em que predominam o processo de fundamentação. 
Quadro 2. Processos do MSLI na UA-5

\begin{tabular}{|l|l|} 
Para maior abrangência da área de estudo, foram escolhidos seis pontos, cada um com um objetivo. Os \\
dois primeiros ((animação)), que é o rio Furnas e a convergência entre o rio Furnas e o rio Betari (PE), \\
são os pontos mais próximos da mineradora de Furnas, que foi a maior mineradora da região (PF). \\
Os dois outros pontos ( (animação)), que foi o rio Betari e o bairro da Serra (PE), são os pontos mais \\
próximos da região ocupada pela população, e estão no estudo para ver se a população contribui para \\
a contaminação do solo (PF). E os outros dois pontos ((animação)), o rio Fria e o rio Betari (PE), são \\
os pontos mais distantes da mineradora e são colocados no intuito de ver se há realmente o transporte \\
de íons metálicos $(\mathbf{P F})$.
\end{tabular}

O Quadro 2 traz a UA-5, a qual contém um mapa para demonstrar os pontos de coleta de amostras ao longo dos rios Furnas e Betari. O aluno expositor inicia sua fala enunciando que havia seis pontos de amostragem, para em seguida salientar e caracterizar cada um deles, relacionando suas localizações com motivações de estudo. A ordem de estruturação dos pontos é guiada pelo texto escrito presente no slide, sendo possível identificar ambos os processos de estruturação e de fundamentação do MSLI. As características inerentes a cada um deles serão discutidas a seguir.

No trecho inicial, "Os dois primeiros ((animação)), que é o rio Furnas e a convergência entre o rio Furnas e o rio Betari", predomina um processo de estruturação, e é possível assim classificá-lo devido à presença de momentos em que o estudante ilustra elementos gráficos e estruturas sinalizadoras da inscrição em sua fala. Inicialmente, os pontos de amostragem são destacados no fragmento "Os dois primeiros", em que o aluno se refere aos pontos de coleta um e dois. Esse trecho representa o momento em que o estudante elabora os pontos citados como estruturas sinalizadoras, já que ele está salientando estruturas no mapa que posteriormente poderão se tornar um sinal.

Apesar de agrupar dois pontos no fragmento de fala, o aluno expositor fez uso de animações, para que cada ponto fosse salientado e estruturado individualmente, e assim criar uma significação adequada do que cada ponto representa. O movimento de animação se dá pelo surgimento de uma flecha que liga cada ponto no mapa ao texto escrito referente no slide. Com base no MSLI, a utilização desse recurso semiótico retrata um momento em que o estudante está salientando estruturas sinalizadoras durante o processo de estruturação.

Por ser uma inscrição, a seta animada e o seu sentido na EO também pode ser elucidado com base no MSLI. Como o aluno não cita a animação em sua fala, podemos inferir que o processo de estruturação da seta foi ausente, possivelmente influenciado pela alta familiaridade do aluno expositor, assim como da audiência, com esse tipo de representação. O trecho "Os dois primeiros, que éo rio Furnas e a convergência entre o rio Furnas e o rio Betari" serve como um interpretante para a seta, ou seja, o aluno expositor verbaliza apenas o processo de fundamentação. $\mathrm{O}$ uso desse recurso evidencia ainda a manifestação da habilidade de aplicar recursos semióticos para auxiliar na produção de sentidos, a qual se configura também como uma adequação na inscrição para sua introdução no contexto da EO e deve ser valorizada.

Por fim, os fragmentos "o rio Furnas" e "a convergências entre o rio Furnas e o rio Betari" representam, cada um, indicações ao texto materializado no corpo do slide, ou seja, a presença do elemento gráfico na leitura do estudante.

Os processos de estruturação dos demais pontos de amostragem são semelhantes aos dois primeiros. Os trechos "Os dois outros pontos" (referente aos pontos três e quatro) e "E os outros dois pontos" (referente aos pontos cinco e seis), assim como as animações correspondentes, representam momentos em que o estudante está salientando os quatro pontos de coleta como estruturas sinalizadoras. Já os trechos "o rio Betari", "o bairro da Serra", "o rio Fria" e "o rio Betari", em relação aos pontos três, quatro, cinco e seis, respectivamente, são indicações do texto incorporado no slide, ou seja, nesse momento o estudante está ilustrando elementos gráficos.

O processo de estruturação é importante nesse momento da EO, visto que os pontos de amostragem e o local físico que eles representam influenciam a discussão dos resultados encontrados posteriormente. Após a estruturação, o estudante começa a conectar as estruturas sinalizadoras destacadas com referentes e interpretantes, por meio de processos de fundamentação, associando-os à situação física local do PETAR e justificando sua presença no estudo. Utiliza-se como exemplo o trecho "são os pontos mais próximos da região ocupada pela população, e estão no estudo para ver se a população contribui para a contaminação do solo", no qual é possível identificar a predominância do processo de fundamentação devido à identificação dos elementos característicos do mesmo. O fragmento "são os pontos" indica um momento em que o estudante transpõe as estruturas sinalizadoras destacadas no processo de estruturação (pontos três e quatro) para o processo de fundamentação, transformando-as em sinais.

Ao indicar que os pontos estão na "região ocupada pela população", o aluno expositor está elaborando um elemento referente, já que está citando uma situação física atribuída aos sinais "pontos três e quatro". A partir disso, o fragmento "e estão no estudo para ver se a população contribui para a contaminação do solo" representa a elaboração de um interpretante, que fortalece a relação entre os sinais e o referente. Cabe aqui um questionamento: como o estudante sabia que aquela região era a ocupada pela população? De onde surgiram o referente e o interpretante identificados?

Mapas são inscrições que, apesar da sua perspectiva bidimensional, possuem bastante semelhança com a região que representam. Dependendo do propósito para que foi construído, um mapa pode ainda carregar demarcações que auxiliam o leitor na percepção e identificação de aspectos que, sem esses recursos, dificilmente seriam percebidos. A natureza dessas demarcações é variada, podendo ser símbolos, e o que eles representam é explicitado em legenda que acompanha a inscrição.

O mapa utilizado na UA-5 (Figura 5) possui uma legenda para auxiliar a interpretação dos sinais nela demarcados. Segundo a legenda, o símbolo " $\square$ " representa regiões do PETAR com ocupação humana. Entende-se, portanto, que o referente "região ocupada pela população" surge a partir da leitura da legenda. No entanto, durante a apresentação o aluno expositor não leu explicitamente a legenda do mapa para a audiência.

Um exemplo de interpretante em relação ao símbolo que o aluno expositor poderia ter falado seria "no mapa, o símbolo representa a região ocupada pela população". A partir disso, com este sinal estruturado e fundamentado, o estudante poderia utilizar essa informação durante a elaboração de outros sinais, referentes e interpretantes, ou 


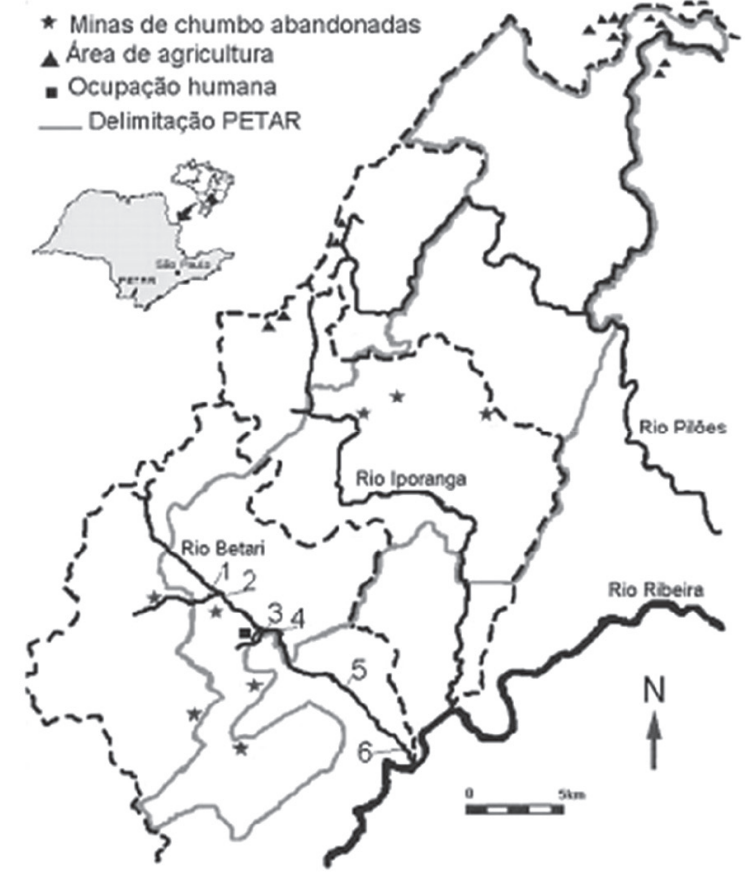

Figura 5. Mapa de localização da área de estudo e dos pontos de amostragem $^{13}$ utilizando na UA-5

seja, realizar uma transferência do referente "região ocupada pela população" do sinal "ø" para os sinais "ponto 3" e "ponto 4", o que de fato ocorreu, mas não de maneira explícita no processo de leitura.

$\mathrm{Na}$ fala do aluno expositor, apenas parte dessa última etapa foi identificada, o que revela a existência de processos de apropriação e familiarização do aluno expositor com os símbolos do mapa, de maneira que a distinção entre o objeto e o que representa o objeto é feita de maneira instintiva, porém sem comprometer o processo de produção de sentidos. Tal familiaridade advém do trabalho com o mapa em outras etapas da disciplina CELCII, como a EO inicial, a construção do pôster e o estudo da estrutura e retórica da linguagem científica do artigo.

Foi possível identificar mais dois processos de fundamentação na UA-5, representados nos trechos "são os pontos mais próximos da mineradora de Furnas, que foi a maior mineradora da região" (pontos um e dois) e "são os pontos mais distantes da mineradora e são colocados no intuito de ver se há realmente o transporte de íons metálicos" (pontos cinco e seis). De forma semelhante ao que foi mencionado anteriormente, quando o estudante enuncia "são os pontos", ele está transportando as estruturas sinalizadoras destacadas no processo de estruturação para o processo de fundamentação, transformando-as em sinais. Os fragmentos "mais próximos da mineradora de Furnas" e "mais distantes da mineradora" representam a associação dos sinais (pontos um e dois, e pontos cinco e seis, respectivamente) a um referente, que é a localização física dos pontos. Por fim, o fragmento "são colocados no intuito de ver se há realmente o transporte de íons metálicos" representa a elaboração de um interpretante que relaciona os pontos cinco e seis, com seu referente. As informações elaboradas durante o processo de estruturação servem para estabilizar o mapa no conhecimento do mundo físico dos estudantes, assim como criar uma melhor visualização da região investigada e como suas características poderiam influenciar nos resultados da pesquisa.

\section{MSLI em Equações}

O Quadro 3 mostra a UA-8, com duas inscrições: um fluxograma, que apresenta uma das etapas experimentais para cálculo da CTC, a qual é calculada por uma equação, que é a outra inscrição presente no slide. No entanto, o estudante aparentemente deixa o fluxograma de lado e se detém na explicação da equação, sendo identificados processos do MSLI na leitura referente a ela.

Durante o transporte da equação do artigo para o slide, o aluno expositor cometeu um erro conceitual. A fórmula apresentada no slide não é utilizada para calcular a CTC, mas a capacidade de metais trocáveis, que, quando somada à acidez trocável, dá o valor da CTC. $\mathrm{O}$ aluno expositor inicia a leitura engajado em um movimento reverso, de redução de uma situação física para uma inscrição, evidenciado no trecho "Essa determinação tem que ocorrer em pH próximo ao natural (referente). Por isso são encontrados os valores de $\mathrm{pH}$ na sua fórmula (sinal)", no qual, a partir de características externas à equação, há projeção de sinais que devem ser encontrados na mesma. Esse fragmento, além de reafirmar a equação como uma matriz de sinais, chama a atenção da audiência e a prepara para a elaboração dos sinais e dos interpretantes, a seguir.

A partir da identificação dos elementos do MSLI, é perceptível a predominância de processos de estruturação no restante da leitura. O trecho "O pH um ((aponta para o slide) ) é o pH da suspensão" conta com a menção a dois elementos gráficos da inscrição, representados nos fragmentos "O $p H$ um" e "o $p H$ da suspensão", que são textos materializados no corpo do slide. No momento em que o estudante aponta para o slide, está salientando a estrutura " $p H_{I}$ " da equação como uma estrutura sinalizadora. O fragmento "o pH da suspensão" também representa um referente para a estrutura destacada. $\mathrm{O}$ trecho seguinte "A suspensão é feita pela amostra com o ácido acético" representa a elaboração de um interpretante para o fluxograma presente no slide, o qual apresenta as etapas de preparo da solução.

No trecho seguinte: "E desse valor de $\mathrm{pH}\left(\left(\mathrm{pH}_{1}\right)\right)$ é tirado o valor de pH somente do ácido acético, que é o pH dois", ao retomar a estrutura " $\mathrm{pH}_{1}$ ", podemos entender que essa se transformou em um sinal, e agora é utilizada para dar continuidade à explicação, conectando-a com o resto da equação, enquanto ilustram-se demais elementos do MSLI. Podemos ainda identificar os fragmentos "o $p H$ dois" e " $p H$ somente do ácido acético" como elaboração de elementos gráficos, materializados no slide. O último fragmento também representa um referente para a estrutura " $\mathrm{pH}_{2}$ " da equação.

Quadro 3. Processos do MSLI na UA-8

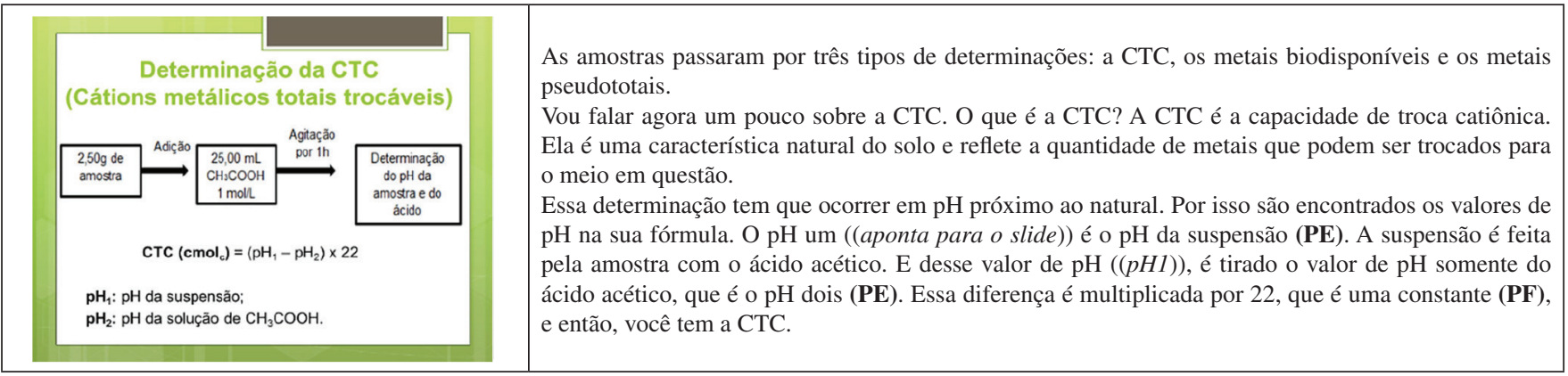


Roth et al. ${ }^{2}$ afirmam que quando a familiaridade de um leitor com os referentes, os sinais e as regras de convenção de uma inscrição se tornam bastante significativas, a relação entre o leitor e o sinal não requer mais atenção do leitor. Um exemplo, é a do aluno expositor com os sinais matemáticos "-" e "x" da equação. Estes são sinais com os quais os estudantes estão em constante contato. Ou seja, a familiaridade com esses sinais é de tamanha extensão, que eles se tornam praticamente invisíveis e, ao vê-los, não se enxerga mais um traço ou um xis, mas o processo de subtração ou multiplicação, respectivamente. Com isso, o aluno expositor apenas elabora o interpretante "é tirado" para o sinal "-" na equação, sem precisar estruturá-lo para a audiência. Esse processo ocorre sem perda de sentido para a audiência, visto que a mesma possui a familiaridade necessária para tal.

No último trecho da UA-8, predomina o processo de fundamentação. Em "Essa diferença é multiplicada por 22, que é uma constante, e então você tem a CTC" foram identificados os três elementos do processo de fundamentação. A partir do fragmento "é tirado", o estudante elabora o sinal "diferença", conectando-o a um novo interpretante "é multiplicada por", interpretante este advindo da familiaridade com os sinais matemáticos. A menção ao número "22" corresponde ao elemento gráfico do processo de estruturação. O fragmento "que é uma constante" representa a conexão do elemento gráfico com um referente, que define o que o número representa fisicamente.

Situações em que o estudante tem alta familiaridade com a inscrição, seus sinais, ou seus referentes podem ser bastante recorrentes durante a leitura de inscrições em uma EO. No entanto, se a audiência não apresentar a mesma familiaridade, esse tipo de leitura não é bem-vinda, pois pode acarretar subtração de informações, já que o sentido é elaborado, mas a sua origem na inscrição não. $\mathrm{O}$ aluno expositor não pode esperar que a audiência enxergue os mesmos sinais que ele durante a leitura de uma inscrição, assim é necessário chamar atenção a esses sinais, estruturá-los e conectá-los com referentes adequados, ou seja, guiar adequadamente a audiência no processo de significação.

\section{MSLI em Tabelas}

O Quadro 4 traz a UA-10, que contém a primeira tabela da EO, que apresenta os resultados obtidos para a avaliação da CTC nas amostras de sedimentos. A leitura de uma tabela deve ser feita considerando a sua estrutura em linhas e colunas, no sentindo de cruzar informações presentes nesses espaços e compará-las. Assim, é preciso observar as linhas e colunas como estruturas sinalizadoras, e nelas procurar outros aspectos que possam ser ligados a algum referente externo a partir da elaboração de interpretantes. Como os pontos de amostragens já haviam sido estruturados anteriormente, na UA-5 (Quadro 2), as informações advindas dessa etapa são utilizadas pelo aluno expositor para justificar aspectos elucidados durante a leitura da inscrição na UA-10.
No trecho "Na tabela, é possível ver que somente o ponto cinco não apresentou essa alta capacidade de troca catiônica" predomina um processo de estruturação, que contém os seguintes elementos: elemento gráfico, no fragmento "o ponto cinco", que faz menção a uma das células da tabela; elemento disposição perceptiva, no fragmento "é possível ver", quando o estudante chama a atenção da audiência para algo que pode resultar em alguma informação; e elemento estrutura sinalizadora, no trecho "somente o ponto cinco", em que o estudante salienta o ponto cinco, como o único que não apresentou alta CTC. Essa inferência também pode ser um sinal para que a audiência deduza que os demais pontos apresentaram alta CTC.

O fragmento "somente o ponto cinco não apresentou essa alta capacidade de troca catiônica" pode ser considerado ainda como um interpretante, que representa uma conclusão obtida a partir da leitura de todos os conjuntos de sinais presentes na tabela. Nos trechos seguintes o aluno expositor enuncia alguns elementos da inscrição que o fizeram chegar nesse interpretante. Dessa forma, uma situação bastante recorrente durante a leitura de inscrições na EO fica evidente: a utilização de inscrições com o objetivo de comprovar um enunciado ou conclusão inicial, ao invés de se obter conclusões e interpretantes, a partir das características exploradas.

No trecho "Damos destaque também ao ponto um, que foi o que apresentou maior CTC, que foi igual a 19. O ponto um, lembrando, é o ponto mais próximo da mineradora de Furnas", foi possível identificar um processo de estruturação seguido de um processo de fundamentação, o que é adequado para o contexto da EO. O processo de estruturação conta com menções a: elemento gráfico, nos fragmentos "ao ponto um" e "igual a 19"; elemento disposição perceptiva, quando o estudante enuncia "Damos destaque", evidenciando o modo como o aluno percebe a inscrição e quais aspectos são considerados por ele durante a leitura, além de direcionar o olhar da audiência para aspectos da inscrição que deveriam ser percebidos; estruturas sinalizadoras, no fragmento "ao ponto um, que foi o que apresentou maior CTC", em que o estudante está salientando a primeira linha da tabela.

As informações enunciadas até então são justificadas na segunda parte do trecho, por meio do processo de fundamentação, que reafirma a estrutura "ponto um" como um sinal, e conecta-o à um referente físico: "é o ponto mais próximo da mineradora de Furnas". Tais informações são advindas da leitura do mapa na UA-5 (Quadro 2). Já que o estudante não necessita mais estruturar o ponto um como uma estrutura sinalizadora, todo o trecho também pode ser visto como um interpretante, que visa justificar o porquê de o ponto um ter o maior valor de CTC.

É possível observar ainda no trecho "E aqui está se mostrando os pontos de amostragem, porque ( ( a CTC)) é uma característica do solo e não de cada metal." a presença dos seguintes elementos: estrutura sinalizadora, identificado em "E aqui está mostrado os pontos de amostragem", em que o estudante está salientando a coluna de pontos de amostragem como uma estrutura que pode prover informações;

Quadro 4. Processos do MSLI na UA-10

\begin{tabular}{|c|c|c|}
\hline \multicolumn{2}{|c|}{$\begin{array}{l}\text { Tabela 1: Valores da CTC efetiva nas amostras de } \\
\text { sedimento. }\end{array}$} & \multirow{7}{*}{$\begin{array}{l}\text { Bom... Após essa análise foi feita a análise dos resultados e a discussão. Vamos começar de novo pela } \\
\text { CTC. A CTC é considerada de alta capacidade de troca catiônica quando seus valores são acima de cinco. } \\
\text { Na tabela, é possível ver que somente o ponto cinco não apresentou essa alta capacidade de troca catiônica } \\
\text { (PE). E aqui está se mostrando os pontos de amostragem, porque }((a C T C) \text { ) é uma característica do solo } \\
\text { e não de cada metal. Damos destaque também ao ponto um, que foi o que apresentou maior CTC, que } \\
\text { foi igual a } 19 \text { (PE). O ponto um, lembrando, é o ponto mais próximo da mineradora de Furnas (PF). }\end{array}$} \\
\hline Pontos de amostragem & CTC efetiva ( $\mathrm{cmol}^{\left.-\mathrm{kg}^{-1}\right)}$ & \\
\hline 1 & 19,0 & \\
\hline 2 & 9,9 & \\
\hline 3 & 7.5 & \\
\hline $\begin{array}{l}4 \\
5\end{array}$ & $\begin{array}{c}12,4 \\
2,9\end{array}$ & \\
\hline 6 & 10.6 & \\
\hline
\end{tabular}


interpretante, quando o estudante explica o porquê de haver uma coluna com pontos de amostragens por meio da elaboração do fragmento " $((a C T C))$ é uma característica do solo e não de cada metal".

\section{MSLI em Gráficos}

O Quadro 5 apresenta a transcrição e a identificação dos processos do MSLI na leitura do único gráfico presente na EO.

A UA-13, no Quadro 5, apresenta a relação de proporcionalidade que existe entre os metais biodisponíveis e a CTC. O estudante inicia apresentando essa afirmação, e então, no trecho "Aqui fica claro, a partir do gráfico, essa relação de proporcionalidade", toma o gráfico em sua totalidade como um sinal da proporcionalidade entre a CTC e a concentração de metais biodisponíveis, que é o referente, ou situação física retratada na inscrição.

O estudante tenta demostrar como o gráfico clarifica a relação de proporcionalidade entre a CTC e a concentração de metais biodisponíveis no sedimento, assim pronunciando: "Para o caso dos metais biodisponíveis, que é essa reta, estes são os valores da soma de cada valor, de todos os metais. E aqui embaixo, há os valores da CTC'. O processo do MSLI predominante nesse trecho é o de estruturação. A leitura do gráfico começa pela sua legenda interna, enumerando um elemento gráfico, identificado no fragmento "Para o caso dos metais biodisponíveis", que são palavras materializadas na legenda. Em seguida, no fragmento "que é essa reta", o estudante toma como estrutura sinalizadora a curva que representa os metais biodisponíveis, de acordo com a legenda. A segunda curva do gráfico também foi salientada como uma estrutura sinalizadora, no fragmento " $E$ aqui embaixo". Cada uma das curvas foi associada a um referente, nos trechos "soma de cada valor, de todos os metais" e "há os valores da CTC", que é o que cada uma daquelas estruturas sinalizadoras, enquanto sinais, representam: as concentrações dos metais biodisponíveis e a CTC, respectivamente. Essa leitura, no entanto, não foi suficiente para clarificar a relação pretendida, e será comentada com mais detalhes na seção "MSLI: Potencialidades e Limitações".

Por fim, temos o trecho "Fica claro o decréscimo das concentrações e também a oscilação no ponto quatro". Nesse trecho, o estudante está associando o gráfico com uma tabela da UA-11, criando uma representação da diminuição da concentração ao longo do percurso do rio, juntamente com a oscilação, sobre a qual ele falou naquela unidade. O processo de estruturação também é predominante, com a identificação dos elementos gráficos no fragmento "ponto quatro" e disposição perceptiva no trecho "Fica claro". Ao serem elucidados, tais elementos auxiliam a audiência na verificação, pela inscrição, de que a concentração diminuía seguindo o percurso do rio, mas que também ocorria uma oscilação em determinado ponto. O decréscimo e a oscilação, ilustrados no fragmento, são assim representações do elemento referente, ou seja, a situação física que o gráfico está tratando.

\section{MODELO SEMIÓTICO DE LEITURA DE INSCRIÇÕES: POTENCIALIDADES E LIMITAÇÕES}

A Tabela 1 resume a quantificação de elementos dos processos do MSLI, identificadas em cada UA, inclusive daquelas que não foram discutidas no texto (UA-6, UA-11 e UA-12). As linhas sombreadas foram obtidas a partir das somas dos resultados acima delas. Dessa forma, "Total - Estruturação" é a soma dos elementos gráfico, disposição perceptiva e estrutura sinalizadora, encontrados naquela UA, e "Total - Fundamentação" é a soma dos elementos sinal, referente e interpretante, encontrados naquela UA. É importante ressaltar que a inserção da Tabela 1 nesse momento não objetiva realizar a quantificação de aspectos qualitativos relatados na seção anterior, mas sim deixar mais clara a discussão acerca das potencialidades e limitações do MSLI.

Na UA-6 foi apresentado um esquema para o percurso de um rio, no qual foi predominante o processo de estruturação. Nas UA-11 e UA-12 foram apresentadas, respectivamente, uma tabela com os resultados da análise da concentração de metais pseudototais nos sedimentos ao longo dos rios Furnas e Betari e uma tabela com os resultados da análise de metais biodisponíveis no sedimento dos rios Furnas e Betari. Na tabela da UA-11, foram identificados um processo de estruturação e dois processos de

Quadro 5. Processos do MSLI na UA-13

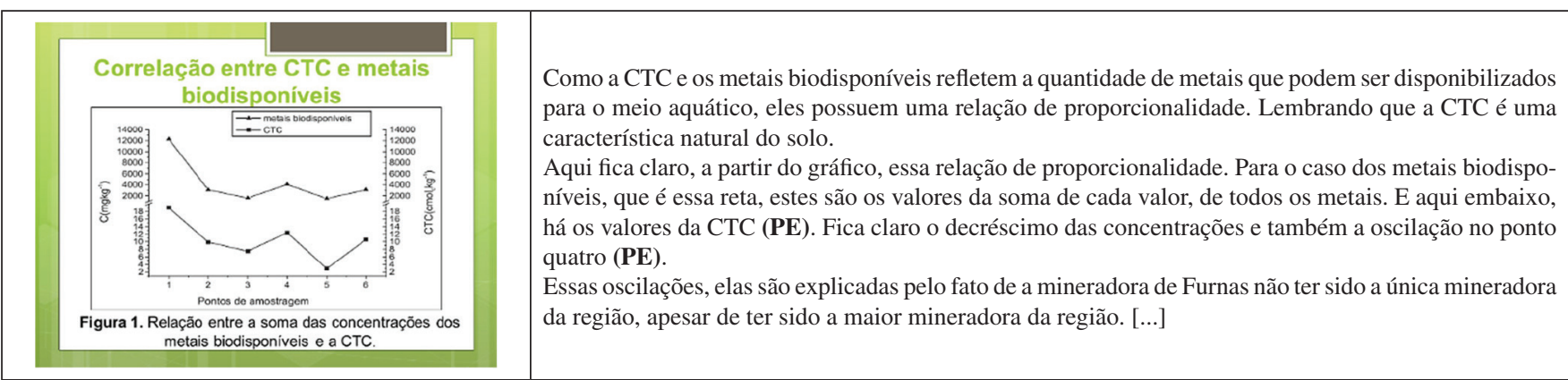

Tabela 1. Elementos do MSLI identificados nas UA

\begin{tabular}{|c|c|c|c|c|c|c|c|}
\hline Elementos & UA-5 & UA-6 & UA-8 & UA-10 & UA-11 & UA-12 & UA-13 \\
\hline Gráfico & 6 & 3 & 5 & 3 & 2 & 2 & 2 \\
\hline Disposição Perceptiva & 0 & 1 & 0 & 2 & 3 & 1 & 1 \\
\hline Estrutura Sinalizadora & 6 & 0 & 1 & 3 & 5 & 3 & 2 \\
\hline Total - Estruturação & 12 & 4 & 6 & 8 & 10 & 6 & 5 \\
\hline Sinal & 6 & 0 & 3 & 1 & 4 & 2 & 0 \\
\hline Referente & 3 & 2 & 4 & 1 & 2 & 3 & 4 \\
\hline Interpretante & 2 & 0 & 3 & 3 & 4 & 2 & 0 \\
\hline Total - Fundamentação & 11 & 2 & 10 & 5 & 10 & 7 & 4 \\
\hline
\end{tabular}


fundamentação. Na tabela da UA-12, o processo de fundamentação foi predominante.

Com base nas relações encontradas durante a verificação da presença de elementos do MSLI e nos dados que constam na Tabela 1, discutiremos a seguir, as potencialidades e limitações do MSLI para proporcionar um melhor entendimento da produção de gêneros orais no ensino de química.

Os gêneros orais, como objetos de ensino, compreendem três dimensões ensináveis: a situação de comunicação, a organização interna da exposição e as características linguísticas. ${ }^{16} \mathrm{~A}$ situação de comunicação é o momento em que o gênero se materializa em texto, numa situação real de uso. A organização interna diz respeito às etapas da realização do gênero oral. Já as características linguísticas são os recursos que o expositor utiliza para a produção de sentidos.

De certo modo, todas as dimensões ensináveis se relacionam com a produção de sentidos a partir da leitura de inscrições no contexto de uma EO. O aluno expositor precisa empregar recursos linguísticos adequados, a fim de que o conteúdo abordado seja recebido de forma clara pela audiência, facilitando, assim, a produção de sentidos pela mesma. A organização interna de um gênero oral, que na EO se caracteriza geralmente por abertura, introdução, desenvolvimento, recapitulação, conclusão e encerramento, visa proporcionar uma abordagem mais didática ao conteúdo tratado. ${ }^{16}$

Voltando o nosso olhar para a situação comunicativa, ela possui os seguintes parâmetros: quadro espaço-temporal, interlocutores e objetivos, que, para a EO analisada, se caracterizam na sala de aula, onde um estudante, que se põe no papel de especialista, tem o objetivo de apresentar resultados obtidos em uma pesquisa científica aos demais colegas que, juntamente ao professor, se colocam como plateia e, presumivelmente, leigos no assunto. Segundo Dolz et al. ${ }^{16}$ essa visão da relação entre alunos e professor é dita bipolar, no entanto, Chaves ${ }^{17}$ define-a como tripolar, já que o professor, geralmente, não se comporta como alguém que vai aprender determinado conteúdo, mas que vai avaliar a performance do expositor ou, até mesmo, corrigir aspectos da sua apresentação. Pensando as inscrições como uma matriz de sinais, os significados produzidos a partir de sua leitura carregam perspectivas dos seus produtores, assim como também do contexto em que estão sendo utilizadas. Modificações na situação comunicativa da EO alteram, consequentemente, a forma como as inscrições são abordadas.

Por exemplo, se a audiência é leiga, o aluno expositor deve se preocupar não apenas com os sentidos produzidos a partir da inscrição, mas também com a forma como reproduzirá esses sentidos durante a sua enunciação, o que demandará a elaboração de mais recursos semióticos e um apoio maior do seu discurso nas inscrições. Já, se a audiência é familiarizada com o conteúdo tratado na apresentação, o aluno expositor precisará elaborar menos recursos semióticos durante a leitura de inscrições, e consequentemente, seu discurso poderá se distanciar um pouco da estrutura interna das inscrições. É papel do aluno organizar o conhecimento e produção de sentidos, considerando também a audiência.

Com base nesse entendimento, é importante ressaltar que não nos cabe indicar o que é um processo de produção de sentidos certo ou errado, mas sim, de acordo com o contexto e situação comunicativa da EO, o que é adequado. Uma das potencialidades do MSLI reside em facilitar a visualização da adequação da EO à situação comunicativa estabelecida na sala de aula, o que foi verificado para a maior parte da exposição analisada com base nas características descritas a seguir.

Em todas as UA foi possível identificar processos de estruturação e processos de fundamentação, o que era esperado para o contexto da produção do gênero EO na disciplina de CELCII, que considera a audiência leiga. $\mathrm{O}$ aluno expositor não pode esperar que os espectadores enxerguem a inscrição da mesma forma que ele, sendo necessário que durante a leitura seja dada atenção às estruturas sinalizadoras para elaboração de interpretantes apropriados para visualização do problema de pesquisa, o procedimento experimental e os resultados do artigo no qual a produção da EO se baseava.

A identificação da predominância de processo de estruturação ou de fundamentação em diferentes momentos da EO corrobora ainda com a sua adequação à situação comunicativa. Observando os dados presentes na Tabela 1, nota-se que em maior parte da apresentação a frequência entre elementos dos processos de estruturação (EPE) e elementos do processo de fundamentação (EPF) é semelhante, com os EPE se sobressaindo em quase todas as UA, o que era esperado. Os EPF predominaram durante a leitura da equação na UA-8 (Quadro 3), devido à familiaridade do aluno expositor e da audiência com algumas particularidades da equação e do fluxograma (criado pelos integrantes do grupo que elaboraram a EO) presentes naquela UA, e durante a leitura da tabela da UA-12, devido à sua similaridade com a tabela presente na UA-11, que faz com que o aluno expositor reduzisse o processo de estruturação.

A identificação dos elementos do MSLI revela ainda problemas na leitura do gráfico da UA-13 (Quadro 5). O estudante salientou as curvas do gráfico com a finalidade de mostrar a proporcionalidade entre a CTC e a concentração dos metais biodisponíveis. No entanto, essa leitura não foi suficiente para guiar a audiência no processo de enxergar tal relação. Seria necessário explicitar no gráfico que quando a concentração de metais biodisponíveis diminui é porque a CTC também diminui, já que, segundo Cotta et al., ${ }^{13}$ a disponibilidade dos metais nos sedimentos depende de quão forte é a interação ligante/ substrato geoquímico, sendo esse o único momento em que a EO foge da adequação esperada.

Quando no início da leitura do gráfico o estudante toma o gráfico por si só como um sinal da relação de proporcionalidade entre a CTC e a concentração de metais, um aspecto preocupante do trabalho com inscrições se elucida. As inscrições têm um papel importante para que os enunciados sejam transformados em fatos confiáveis e, quando isso ocorre, estes passam a ser utilizados na produção de novos conhecimentos e fatos. Entretanto, ao passar por esse processo, as inscrições podem acabar sendo confundidas ou até mesmo consideradas como substitutos autênticos dos próprios fenômenos das quais surgiram. ${ }^{1} \mathrm{E}$ necessário saber que as inscrições não representam em sua totalidade a realidade que retratam, nem mesmo as inscrições que apresentam grande semelhança com o MFO, como as fotografias. Essa distorção acaba por resultar em leituras e interpretações inadequadas acerca dos fenômenos estudados, como a que ocorreu na UA-13 (Quadro 5).

Somando as quantidades de EPE e EPF e dividindo por oito obtemos a média desses elementos por inscrição com função complementar. Divide-se por oito, pois apesar de termos sete UA na Tabela 1, na UA-8 (Quadro 3) estão presentes duas inscrições com a função mencionada. Assim, são obtidos os seguintes valores: 6,4 EPE e 6,1 EPF por inscrição. A semelhança entre esses valores sugere que o aluno expositor conseguia transportar as estruturas salientadas no processo de estruturação para o processo de fundamentação, estabelecendo assim relações satisfatórias entre as inscrições e os fenômenos que elas representam durante a maior parte do tempo da EO.

Outra potencialidade do MSLI é que ele revela de maneira simples as camadas de significação envolvidas e os aspectos da produção de sentidos em leituras de inscrições em EO, por exemplo, durante a leitura do mapa na UA-5 (Quadro 2). O Modelo ajudou a perceber que o aluno expositor havia interiorizado a legenda da inscrição, utilizando as informações proveniente da mesma para elaborar interpretantes que justificavam os pontos de amostragem. Outro exemplo se refere à leitura da tabela da UA-10 (Quadro 4) e a leitura do gráfico na UA-13 (Quadro 5). A partir da identificação dos elementos de processo de estruturação e de fundamentação, fica claro que o estudante enuncia 
inicialmente uma conclusão geral da inscrição (interpretante), seguida então das características e estruturas que resultam em tal assertiva.

Os exemplos descritos para as UA-10 (Quadro 4) e UA-13 (Quadro 5) entram em contraponto com perspectivas presentes na literatura, as quais realizam estudos a partir de atividades investigativas com inscrições, quando os estudantes e cientistas são requisitados a resolverem problemas ou responderem questões que envolvam inscrições. ${ }^{2,14}$ Nesses trabalhos, é bastante comum que os sujeitos estruturem e fundamentem a inscrição, para então chegarem a algum resultado e conclusão, que é o inverso do que ficou evidenciado a partir da descrição da UA-10 e UA-13. Fica assim evidente o potencial do MSLI em descrever e elucidar de maneira coerente o uso e a leitura de inscrições em situações até então poucos exploradas, que são os gêneros orais.

Em relação às limitações do Modelo, a sua utilização depende essencialmente da verbalização dos elementos dos processos de estruturação e fundamentação. Dessa forma, as inscrições decorativas e ilustrativas, as quais não apresentam elementos que demonstram como se deu a trajetória de leitura, impedem o analista de enxergar com clareza como foi realizada a produção de sentido. É importante esclarecer que a falta da indicação desses recursos, que representam os elementos do MSLI, não reflete uma ausência de leitura. De fato, durante a utilização e leitura de inscrições decorativas e ilustrativas ocorrem processos complexos de significação, com a presença das etapas de estruturação e fundamentação, no entanto, estes estão internalizados, não podendo dessa forma serem descritos neste trabalho.

Para as inscrições decorativas e ilustrativas, a produção de sentidos requer uma participação mais ativa da audiência, visto que, na função decorativa, a inscrição não é citada pelo aluno expositor, e na função ilustrativa, ela é meramente indicada. Ou seja, devido aos recursos disponibilizados explicitamente pelo aluno expositor, a audiência necessita procurar pistas no contexto em que a inscrição se encontra, como aspectos nelas presentes, o texto verbal oral do aluno expositor, outros textos encontrados no slide etc. Ao final, o sentido produzido é fruto de dois fatores: a disposição perceptiva da audiência, a qual influencia na busca pelas pistas; e a familiaridade com a inscrição e os referentes.

É importante ressaltar que não se espera a ausência de inscrições decorativas e ilustrativas na EO, mas o seu uso de forma oportuna. Por exemplo, caso a tabela da UA-10 e o gráfico da UA-13 tivessem função ilustrativa ou decorativa, a audiência teria imagens de como foi realizada a organização dos dados, porém, estaria privada de recursos que possibilitariam enxergar na inscrição as características que validam os resultados da pesquisa.

\section{CONSIDERAÇÕES FINAIS}

Segundo Latour e Woolgar, ${ }^{1}$ a noção de inscrição vem descrever as representações visuais materiais dos objetos de estudo da pesquisa científica, que têm como papel evidenciar conclusões, embasar justificativas e fortalecer argumentos, promovendo a confiabilidade necessária ao conhecimento científico produzido. Apesar da centralidade das inscrições para a ciências, a comunicação científica e o ensino de ciências, é comum estudantes apresentarem dificuldades no seu uso e interpretação, advindas especialmente da falta de oportunidades de práticas autênticas que familiarizem e desenvolvam tais habilidades comunicativas baseadas em inscrições.

A partir disso, aponta-se a efetividade de atividades baseadas na produção de EO, entre outros gêneros orais, para promover a leitura e interpretação satisfatória de inscrições, e a criticidade frente às mesmas. Dessa forma, o objetivo geral deste trabalho foi ilustrar a utilização do MSLI de Roth e Bowen, ${ }^{4}$ para analisar o uso e a leitura de inscrições no ensino de química durante a produção do gênero
EO, elaboradas a partir da leitura de artigos sobre a temática química ambiental, observando-se as potencialidades e limitações do MSLI.

A partir desse objetivo, foi possível observar que o MSLI oferece uma série de elementos para análise da produção de EO no ensino de química, entre outros gêneros verbais orais, assim como textuais. $\mathrm{O}$ Modelo auxilia na identificação do modo como o estudante aborda as diferentes inscrições durante a EO, quanto a sua adequação à situação comunicativa, sendo possível identificar três situações. A primeira situação é esperada, na qual estão presentes ambos as etapas do MSLI: processo de estruturação seguido de fundamentação, ou ainda, o inverso. Essa situação é a mais adequada à situação comunicativa estabelecida comumente para uma EO, já que nela a audiência, tida como leiga, consegue perceber quais elementos da inscrição geram os enunciados. Essa situação geralmente ocorre quando há uma semelhança entre as quantidades de EPE e EPF.

A segunda situação é aquela em que é possível identificar predominância do processo de fundamentação, o que revela uma alta familiaridade do estudante com os aspectos da inscrição e com o que ela representa, de maneira que não consegue recuar e realizar um processo de estruturação. Essa situação se adequa a contextos nos quais a audiência já possui alguma familiaridade com a inscrição e o fenômeno nela representado, e a partir disso há predominância de EPF. A terceira situação se refere aos contextos nos quais é possível identificar a predominância do processo de estruturação, o que indica que o aluno não consegue transpor as características salientadas, para o processo de fundamentação, resultando assim em uma produção de sentidos inadequada à situação comunicativa estabelecida comumente para uma EO. Essa situação ocorre quando há predominância dos EPE.

O MSLI também auxilia na percepção de como os estudantes enxergam as inscrições: como um conjunto de dados a ser explorado ou apenas como ilustradores do conhecimento científico. Na EO analisada, o aluno expositor claramente as enxerga como um conjunto de dados, de maneira que as utiliza para elaborar conclusões e justificativas, e para comprovar e argumentar acerca de enunciados previamente realizados. A EO em si auxilia no alcance desse aspecto, já que ao serem inseridos em uma prática que os levem a pensar em termos de inscrições, a natureza e o propósito delas para a ciência tornam-se mais claros para os estudantes, facilitando também a sua criação e compreensão.

Além do mais, sobre as potencialidades da EO, por ser um gênero que carrega perspectivas dos discursos didático e científico, a sua produção na sala de aula dá margem para os estudantes trabalharem com diferentes tipos de inscrições, que vão desde o MOF até o MCT, o que fomenta um melhor desenvolvimento das habilidades comunicativas com inscrições e a capacidade de articular diversas formas de representação. O MSLI pode, por fim, auxiliar na identificação dessas habilidades, tais quais: aplicar recursos semióticos para a produção de sentidos e questionar e refletir sobre o modo como a inscrição foi construída, assim como produzir inscrições, adequar inscrições a situações diferentes daquelas em que foram concebidas.

Cabe ainda ressaltar as possibilidades pedagógicas do Modelo, como um instrumento que pode ser usado para a instrução acerca de como realizar leituras adequadas de inscrições, em cursos de graduação de química, entre outros, de forma que mais espaços e atividades autênticas, essenciais para uma formação profissional plena, permeiem os ambientes de ensino.

\section{MATERIAL SUPLEMENTAR}

As UA não discutidas neste texto encontram-se disponíveis gratuitamente em http://quimicanova.sbq.org.br, na forma de arquivo PDF. 


\section{AGRADECIMENTOS}

Ao CNPq (421940/2018-2) e à FAPESP (2018/23819-9 e 18/23809-3).

\section{REFERÊNCIAS}

1. Latour, B.; Woolgar, S.; A vida de laboratório: a produção dos fatos científicos, Relume Dumará: Rio de Janeiro, 1997.

2. Roth, W. M.; Pozzer-Ardenghi, L.; Han, J. Y.; Critical graphicacy: understanding visual representation practices in school Science, vol. 26, Springer: Dordrecht, 2005.

3. Paula, H. F.; Alves, E. G.; Anais do VII Encontro Nacional de Pesquisa em Educação em Ciências, Florianópolis, Brasil, 2009.

4. Roth, W. M.; Bowen, G. M.; Journal for Research in Mathematics Education 2001, 32, 159.

5. Lima, M. S.; Queiroz, S. L.; Quim. Nova Esc. 2019, 41, 300.

6. Cabral, P. F. O.; Peron, K. A.; Queiroz, S. L.; Quim. Nova 2019, 42, 221.

7. Roth, W. M.; International Journal of Computers for Mathematical Learning 2003, 8, 161.
8. Azevedo Netto, C. X.; Informação \& Sociedade 2002, 12, 1.

9. Kress, G.; Multimodality: a social semiotic approach to contemporary communication, Routledge: London, 2009.

10. Kress, G.; Van Leeuwen, T.; Reading images: the grammar of visual design, $1^{\text {st }}$ ed., Routledge: London, 1996.

11. Fonseca, V. A. C.; Dissertação de Mestrado, Universidade Federal de Minas Gerais, Brasil, 2014

12. Roth, W. M.; Mcginn, M. K.; Review of Educational Research 1998, 68 , 35 .

13. Cotta, J. A. O.; Rezende, M. O. O.; Piovani, M. R.; Quim. Nova 2006, $29,40$.

14. Keller, S. K.; Dissertação de Doutorado, University of Central Florida, Estados Unidos, 2008.

15. Pozzer, L. L.; Roth, W. M.; J. Res. Sci. Teach. 2003, 40, 1089.

16. Dolz, J.; Schneuwly, B.; Pietro, J. F. D.; Zahnd, G. Em Gêneros orais e escritos na escola: tradução de trabalhos de Bernard Schneuwly, Joaquim Dolz \& colaboradores; Rojo, R. H. R., Cordeiro, G. S., eds.; $3^{\text {a }}$ ed., Mercado de Letras: Campinas, 2004, pp. 183-212.

17. Chaves, M. H. R.; Dissertação de Mestrado, Universidade Federal do Pará, Brasil, 2008. 